ORIGINAL ARTICLE

\title{
Impact of zinc supplementation in children with acute diarrhoea in Turkey
}

\author{
P Boran, G Tokuc, E Vagas, S Okłem, M K Gokduman
}

See end of article for authors' affiliations

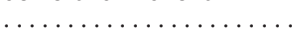

Correspondence to: Perran Boran, Akin sok Hatboyu Cikmazi, Ortac apt 13/12, Saskinbakkal, Istanbul, 34740, Turkey; drperran@yahoo.com

Accepted

28 November 2005

Published Online First

14 December 2005
Objective: Zinc deficiency is prevalent in children in developing countries. Supplemental zinc provides therapeutic benefits in diarrhoea. Our aim was to evaluate the effect of daily zinc supplementation for 14 days on diarrhoea duration, severity, and morbidity in children.

Methods: In a randomised, open label non-placebo controlled trial, we assessed the efficacy of providing zinc sulfate to 6-60 month old children with acute diarrhoea for 2 weeks followed by 3 months of morbidity surveillance. Children were randomly assigned to zinc $(n=150)$ and control $(n=130)$ groups and received 15-30 mg elemental zinc daily.

Results: Supplemented children had significantly improved plasma zinc levels by day 14 of therapy. Zinc deficiency was observed in $2.6 \%$ of the treatment and $3.3 \%$ of the control group. The mean duration of diarrhoea after starting supplementation was $3.02 \pm 2$ days in the zinc group and $3.67 \pm 3.2$ days in the control group. There was no significant difference in diarrhoea duration by treatment group $(p>0.05)$. The number of stools after starting supplementation was $5.8 \pm 3.7$ and $5.1 \pm 3.9$ on day $1,2.9 \pm 1.6$ and $3.0 \pm 2.2$ on day 2 , and $1.8 \pm 1.1$ and $1.6 \pm 0.9$ on day 3 in the zinc and control groups, respectively. There was no significant difference in diarrhoea severity by treatment group ( $p>0.05)$. No significant effect was found on the incidence and prevalence of diarrhoea in the zinc compared with the control group.

Conclusion: Our data indicate that supplementing children with acute diarrhoea in Turkey with 3 RDA of elemental zinc for 14 days improved neither diarrhoea duration nor severity despite significant increments in plasma zinc.
W orldwide, diarrhoeal diseases are a leading cause of paediatric morbidity and mortality, with 1.5 billion episodes and 1.5-2.5 million deaths estimated to occur annually among children below 5 years of age. ${ }^{12}$ In Turkey, approximately 30000 deaths occurred in 1986, but the estimated rate had declined to $10000 /$ year by $1992 .^{3-5}$ Although the total number of deaths has been reduced substantially, diarrhoea still accounts for about $6 \%$ of all deaths in children below 5 years of age. ${ }^{3-5}$

In 1992, the Center for Disease Control (CDC) prepared the first national guidelines for managing childhood diarrhoea and further data have since emerged regarding diarrhoea treatment, including the importance of zinc supplementation. ${ }^{6}$ Multiple reports, all from the developing countries, have linked diarrhoea and abnormal zinc status, including increased stool zinc loss, negative zinc balance, and reduced tissue levels of zinc. ${ }^{78}$ It is thought that zinc deficiency might play a role in childhood diarrhoea and zinc supplementation might be of benefit either for improving outcomes or as prophylaxis against diarrhoea. Possible mechanisms for the effect of zinc treatment on diarrhoea include improved absorption of water and electrolytes by the intestine, faster regeneration of gut epithelium, increased levels of enterocyte brush border enzymes, and enhanced immune response, leading to early clearance of diarrhoeal pathogens from the intestine..$^{9-11}$

In the randomised controlled trials of zinc supplementation that evaluated prevention of diarrhoea, significantly lower incidences of diarrhoea occurred in the zinc groups than in the controls. ${ }^{12-15}$ A pooled analysis that includes most of these trials revealed $18 \%$ less diarrhoea in the zinc supplemented children. ${ }^{16}$ Furthermore, zinc supplements given for 14 days during and after diarrhoea can reduce the incidence of diarrhoea in the subsequent $2-3$ months. ${ }^{17}$ The
World Health Organization (WHO) has recommended that zinc is used in the treatment of persistent diarrhoea, which means trials on persistent diarrhoea are no longer appropriate. $^{18}$

We aimed to evaluate the impact of zinc supplementation on acute diarrhoea severity and duration, and conduct morbidity surveillance for 3 months after supplementation was given.

\section{METHODS}

We carried out a home based, prospective, randomised, open label, non-placebo controlled trial in 280 children aged 660 months from April 2004 to January 2005.

The study protocol was approved by the respective institutional ethics committees at the Dr. Lutfi Kirdar Kartal Research and Training Hospital, Istanbul. Eligible children were included after informed consent was received from at least one of the parents.

Children with acute diarrhoea of $<14$ days pre-enrolment duration were recruited for the study from the paediatric emergency and outpatient clinic. Exclusion criteria included refusal of consent, malnutrition, medical conditions requiring hospitalisation, and having received anti-diarrhoea medications and antibiotics.

Children were randomly assigned to one of two groups. Block randomisation was carried out using eight numbers in each block to ensure that equal numbers of patients entered each group after every eight patients. Diarrhoea was managed according to WHO guidelines. ${ }^{19}$ The study group received 3 RDA (recommended dietary allowance) zinc in a syrup once daily ( $15 \mathrm{mg}$ zinc for 6-12 month old children

Abbreviations: CDC, Center for Disease Control; RDA, recommended dietary allowance; WHO, World Health Organization 
and $30 \mathrm{mg}$ for 12-60 month old children) as zinc sulfate for a total of 14 days; the control group received oral rehydration salts solution only. The RDA is $5 \mathrm{mg}$ elemental zinc/day for infants and $10 \mathrm{mg} /$ day for children $1-4$ years old. ${ }^{20}$ Any vomiting or nausea, other possible side effects, and the amount of supplement taken was recorded by the mother. Children were examined by the physician each day at the hospital until the diarrhoea episode had ceased and were then followed up every 7 days by phone call. During each hospital visit, the study physician asked about the child's health, the number and characteristics of all stools passed, and the use of the supplement each day since the last visit. Children were referred to the study physician for reexamination if they had recurrent diarrhoea or evidence of other infection during the study period.

Nutritional status was assessed using weight for height, height for age, and weight for age z scores. The values for each nutritional index were converted into standard deviation (z) scores according to the 2000 CDC growth charts. Apparently healthy children who recovered from the diarrhoea episode within 2 weeks of supplementation had effects on morbidity assessed by surveillance for a subsequent 3 months without further supplementation.

At enrolment and on day 15, non-fasting venous blood was drawn into zinc-free heparinised tubes between 9 am and 4 pm. Plasma was stored at $-20^{\circ} \mathrm{C}$ until analysis. Plasma specimens were analysed for zinc using an atomic absorption spectrophotometer technique. ${ }^{21}$

Diarrhoea was defined as three or more loose stools in a $24 \mathrm{~h}$ period. An episode of diarrhoea was defined as at least l day of diarrhoea, with the final day of the episode being the last day meeting the diarrhoea definition followed by at least $48 \mathrm{~h}$ without diarrhoea. Two consecutive days free from disease were regarded as resolution of previous diarrhoeal illness. Relapse was defined as a new episode of diarrhoea during the study period. Serum zinc concentrations were considered low if they were $<60 \mu \mathrm{g} / \mathrm{dl}$. The trial outcomes included diarrhoea duration, severity, incidence, and prevalence (the number of new episodes of the illness and number of days with the illness, respectively, per total days of observation).

Based on information from previous studies, ${ }^{22}$ a sample size of 130 children per group was calculated to be adequate to detect a $35 \%$ difference in the duration of the current episode of diarrhoea after starting the treatment.

Statistical analyses were completed by using SPSS 10.0 and significance was set at $5 \%$. Analysis of variance and $\chi^{2}$ tests were used to assess differences among groups. The possible covariates included age, sex, nutritional status, initial stool frequency, and initial plasma zinc concentration. We estimated the therapeutic effect of zinc on the incidence and prevalence of diarrhoea episodes by calculating odds ratios and $95 \%$ confidence intervals. The odds ratios were obtained by using logistic regression.

\section{RESULTS}

The children in the two groups were comparable as regards baseline characteristics including age, child feeding practices, nutritional status, maternal literacy, family size, and socioeconomic characteristics. Responses to the socioeconomic survey indicated that about $90 \%$ of the mothers were housekeepers, $90 \%$ of the mothers were between 18 and 35 years of age, family income was above the minimum wage in $60 \%$, and family size was under five in $84 \%$. No significant differences were noted between the two groups $(\mathrm{p}>0.05)$. Five patients in the zinc group and 10 patients in the control group were lost to follow up and the final analysis was performed in the remaining patients. Table 1 details the admission characteristics of the two groups.
Table 1 Baseline characteristics of children enrolled in the zinc and control groups

\begin{tabular}{|c|c|c|}
\hline Characteristics & $\begin{array}{l}\text { Zinc group } \\
(n=150)\end{array}$ & $\begin{array}{l}\text { Control group } \\
(n=130)\end{array}$ \\
\hline Gender (female/male) & $69 / 81$ & $56 / 74$ \\
\hline Age (months) & $27.7 \pm 15.2$ & $24.3 \pm 13.1$ \\
\hline \multicolumn{3}{|l|}{ Birth weight } \\
\hline$<2500 \mathrm{~g}$ & 14 & 9 \\
\hline$>2500 \mathrm{~g}$ & 136 & 121 \\
\hline \multicolumn{3}{|l|}{ Breast feeding } \\
\hline None & 3 & 6 \\
\hline$<6$ months & 45 & 45 \\
\hline$>6$ months & 102 & 79 \\
\hline Initial weight (kg) & $13.5 \pm 3.75$ & $12.06 \pm 2.76$ \\
\hline Initial length $(\mathrm{cm})$ & $89.8 \pm 12.4$ & $85.7 \pm 10.01$ \\
\hline Weight for age $\mathrm{z}$ score & $1.69 \pm 0.82$ & $1.58 \pm 0.75$ \\
\hline Height for age $z$ score & $1.74 \pm 0.75$ & $1.65 \pm 0.8$ \\
\hline Weight for height z score & $1.98 \pm 0.1$ & $1.87 \pm 0.3$ \\
\hline \multicolumn{3}{|l|}{ Stool frequency } \\
\hline $3-5$ & 87 & 64 \\
\hline $6-9$ & 41 & 51 \\
\hline$>10$ & 22 & 15 \\
\hline $\begin{array}{l}\text { Pre-enrolment diarrhoea } \\
\text { duration (days) }\end{array}$ & $2.2 \pm 1.3$ & $2.7 \pm 3.3$ \\
\hline
\end{tabular}

The mean plasma zinc levels at baseline and at the end of the study were $109.6 \pm 22.6$ and $132.7 \pm 35.8 \mu \mathrm{g} / \mathrm{dl}$ in the zinc group and $102.9 \pm 32.3$ and $101.8 \pm 23.7 \mu \mathrm{g} / \mathrm{dl}$ in the control group, respectively. In the zinc group $2.6 \%$ of the children had a plasma zinc concentration below $60 \mu \mathrm{g} / \mathrm{dl}$, and in the control group $3.3 \%$ of the children had a plasma zinc concentration below $60 \mu \mathrm{g} / \mathrm{dl}$. The plasma zinc concentration was significantly higher at the end of the study in the zinc supplemented group $(\mathrm{p}<0.05)$. The difference in plasma zinc between the end of study and baseline concentrations was also substantially higher in the zinc group as compared with the control group $(\mathrm{p}<0.05)$.

Five children $(4.3 \%)$, all in the zinc group, reported vomiting each day immediately after the supplement was given during the first week of supplementation. If the patient vomited within $10 \mathrm{~min}$ after receiving the supplementation, the dose was repeated. The reported data revealed no side effects other than vomiting.

The mean duration of diarrhoea after starting the supplement was $3.02 \pm 2$ days in the zinc group and $3.67 \pm 3.2$ days in the control group. There was no significant difference in diarrhoea duration by treatment group $(\mathrm{p}>0.05)$. Evaluation of the outcomes for the subgroup with low admission plasma zinc levels $(<60 \mu \mathrm{g} / \mathrm{dl})$, who also had the greatest number of stools ( $>10$ stools per day $v 6-9$ and 3-5 stools per day), did not reveal any significant differences $(\mathrm{p}>0.05)$.

The number of stools after starting the supplement was $5.8 \pm 3.7$ and $5.1 \pm 3.9$ on day $1,2.9 \pm 1.6$ and $3.0 \pm 2.2$ on day 2 , and $1.8 \pm 1.1$ and $1.6 \pm 0.9$ on day 3 in the zinc and control groups, respectively. There was no significant difference in diarrhoea severity by treatment group $(p>0.05)$.

Approximately one fifth of the children in the zinc (30/150) and control (25/130) groups in this study no longer had diarrhoea as early as day 1. During the follow-up period, $14.5 \%$ of the children in the zinc group and $13.5 \%$ of the children in the control group had a relapse of diarrhoea. No significant effects was found for the incidence (odds ratio (OR): $1.34 ; 95 \%$ confidence interval (CI): 0.68 to 2.65 ) or prevalence of diarrhoea (OR: 1.06 ; $95 \%$ CI: 0.92 to 1.22 ) in the zinc group as compared with the control group.

\section{DISCUSSION}

Zinc deficiency, which is prevalent in children in developing countries, places children at increased risk of infectious 


\section{What is already known on this topic}

- Zinc deficiency, a prevalent condition in children in developing countries, places these children at increased risk of infectious diseases

- Supplementation trials with zinc have shown zinc has a major effect on diarrhoea related morbidity

- Zinc supplements given for 14 days during and after diarrhoea reduce the duration and severity of treated diarrhoea episodes and can reduce the incidence of diarrhoea in the subsequent 2-3 months

diseases in those regions. During supplementation trials with zinc, the major effect has been shown to be on diarrhoea related morbidity. ${ }^{12-15}$ Although WHO has recommended that zinc is used in the treatment of persistent diarrhoea, more information is needed on the use of zinc supplementation in acute diarrhoea in different settings.

In addition to the preventive trials in which zinc was given on a routine, usually daily, basis for an extended period of time, in other trials zinc was provided as an adjunct to therapy for acute and persistent diarrhoea. The preventive trials are consistent in showing that zinc supplemented children have lower rates of diarrhoea than control children. ${ }^{1422}{ }^{23}$ The trials evaluating the therapeutic effects of zinc for diarrhoea demonstrate that the zinc supplemented children have episodes of shorter duration, a lower number of stools or smaller stool volume, and a reduction in treatment failure or death. ${ }^{8}{ }^{12} 24$

In this study, most children were able to adequately absorb oral zinc sulfate with an increase in plasma levels. Evidence that the zinc was successfully absorbed is provided by the plasma concentration of zinc which by day 15 of therapy had risen significantly in the zinc supplemented groups. However, in contrast to previous studies, our data suggest that supplementing healthy children with acute diarrhoea for 14 days neither improved diarrhoea recovery nor had an impact on morbidity during the subsequent 3 months without further supplementation. It must be recognised, however, that this trial was conducted in ambulatory, apparently healthy children without malnutrition, who had not been hospitalised. Previous trials were conducted with malnourished children with more severe diarrhoea and living in typical developing country settings where the prevalence of subclinical zinc deficiency is approximately $80 \%{ }^{22}$ The trials also selected moderately or severely undernourished children whose growth was stunted. In addition, there may have been differences in therapeutic approach such as supplementation with zinc for longer periods and additional supplementation with multivitamins; the beneficial effect shown in the trials could be the result of a synergistic effect caused by multivitamin supplementation.

In our study, only $2.6 \%$ of the children in the zinc group and $3.3 \%$ of the children in the control group had plasma zinc concentrations below $60 \mu \mathrm{g} / \mathrm{dl}$. Estimates of the prevalence of zinc deficiency in our country vary between $15.7 \%$ and $24 \%^{25} 26$; studies have mainly examined malnourished children with chronic diarrhoea. In a study by Cetin et al, zinc deficiency was seen in $64 \%$ of 42 hospitalised patients with acute diarrhoea; the researchers were unable to explain this high incidence. ${ }^{27}$ A recently published trial from Turkey by Polat et al found a reduction in the severity and duration of diarrhoea following zinc supplementation in a group of malnourished children, who are, however, at risk of zinc deficiency as in developing countries. ${ }^{28}$

\section{What this study adds}

- Supplementing healthy children with acute diarrhoea in Turkey with 3 RDA/day of elemental zinc during 14 days neither improved diarrhoea recovery nor morbidity, despite significant increments in plasma zinc concentrations

- Specific recommendations regarding the use of zinc supplementation in acute diarrhoea should await additional population based studies assessing the role of zinc supplementation in the treatment of children with acute diarrhoea

Previous analyses have shown that zinc supplementation has a greater effect in children with lower plasma zinc concentrations..$^{14} 1617$ The low prevalence of zinc deficiency in our study could be a reasonable explanation for the failure of zinc therapy. It is likely that initial zinc status influences the response to therapy and the benefits of zinc supplementation may be limited to individuals or populations with preexisting zinc deficiency. In the present study, data analysis did not reveal any significant differences $(p>0.05)$ between a low plasma zinc group and a normal zinc group. The differences in diarrhoeal duration and severity were not statistically significant, possibly because the small sample size of the subgroup with low zinc levels was too small to detect a statistically significant difference.

Furthermore, this low percentage of zinc deficiency found in the present study could be because the mean duration of diarrhoea ( $3.02 \pm 2$ days) after starting the supplement is too short time for increased intestinal losses of zinc to cause zinc deficiency in a healthy child.

Approximately one fifth of the children in the zinc group $(30 / 150)$ in our study no longer had diarrhoea as early as the first day of treatment. This rapid recovery from diarrhoea on the first day of intervention complicates interpretation of the results because it seems unlikely that zinc could have influenced clinical outcomes so quickly. Indeed, a previous supplementation trial among children with acute diarrhoea showed that there was only a small, non-significant reduction in the risk of continuing diarrhoea during the first three days of zinc treatment, whereas there was a statistically significant $38 \%$ reduction in the risk of ongoing illness in zinc treated children after the third day of therapy. ${ }^{12}$

Following the recommendations of the pharmaceutical industry, zinc supplements are already widely used for outpatients with diarrhoea and as an adjunct therapy in acute diarrhoea. Well-nourished children with normal serum level of zinc may experience delayed adverse effects following zinc supplementation. Iron deficiency anaemia is the most common nutritional deficiency in the developing world, particularly in preschool children. A significant interaction of zinc absorption with copper and iron has been described and zinc supplementation alone may aggravate the deficiencies of other minerals ${ }^{29}$; measures of iron and copper status would have been helpful in this study, but there were none. Furthermore, Ruel et al found that both the incidence and prevalence of respiratory infection were higher in children who received zinc supplementation. ${ }^{23}$ Schlesinger et al have shown that zinc supplementation inhibits phagocytic and fungicidal activity in malnourished infants. ${ }^{30}$ In studies assessing the effect of zinc supplementation on the developmental levels of infants, Hamadani et al found that the mental development index scores of a zinc treated group were slightly but significantly lower than those of a placebo group $^{31}$ and suggested zinc supplementation in pregnant 
mothers had a negative effect on the mental development of their children at 13 months of age. ${ }^{32}$

In conclusion, our data indicate that supplementing children with acute diarrhoea in Turkey with 3 RDA/day of elemental zinc for 14 days improved neither diarrhoea recovery nor morbidity, despite significant increments in plasma zinc concentrations. We believe that the adverse effects of zinc supplementation should be weighed against the beneficial effect of zinc in reducing diarrhoea. Specific recommendations regarding the use of zinc supplementation in acute diarrhoea should await additional population based studies assessing the role of zinc supplementation in the treatment of children with acute diarrhoea.

\section{Authors' affiliations}

P Boran, G Tokuc, E Vagas, S Oktem, M K Gokduman, Dr. Lutfi Kirdar Kartal Research and Training Hospital, 2nd Clinic of Pediatrics, Istanbul, Turkey

Competing interests: this study was supported by a grant from Berko Pharmacy Ltd

\section{REFERENCES}

1 Kosek M, Bern C, Guerrant RL. The global burden of diarrheal diseases, as estimated from studies published between 1992 and 2000. Bull World Health Organ 2003;81:197-204.

2 Black RE, Morris SS, Bryce J. Where and why are 10 million children dying every year? Lancet 2003;361:2226-34.

3 TC Hukumeti-UNICEF Isbirligi Programi. Turkiye'de anne ve çocuklarin durum analizi, Ulke programi 1991-1995. Ankara: Yenicað Matbassý, 1991:115-28.

4 TC Hukumeti-UNICEF Isbirligi Programi. Turkiye'de anne ve çocuklarin durum analizi. Ankara: Pelin Offset, 1996:134.

5 Ozmert E, Yurdakok K. Dunyada ve Turkiye'de Ishalli Hastaliklar. Katki Pediatri Dergisi 2000;21(1):1-5.

6 King CK, Glass R, Bresee JS, et al. Managing acute gastroenteritis among children: oral rehydration, maintenance, and nutritional therapy. http:// www.cdc.gov/mmwr/preview/mmwrhtml/rr5216al.htm (accessed 15 December 2005).

7 Hambidge KM. Assessing the trace element status of man. Proc Nutr Soc 1988:47:37-44.

8 Sachdev HPS, Mittal NK, Mittal SK, et al. A controlled trial on utility of oral zinc supplementation in acute dehydrating diarrhea in infants. J Pediatr Gastroenterol Nutr 1988;7:877-81

9 Cario E, Jung S, Harder D'Heureuse J, et al. Effects of exogenous zinc supplementation on intestinal epithelial repair in vitro. Eur J Clin Invest 2000:30(5):419-28.

10 Shankar AH, Prasad AS. Zinc and immune function: the biological basis of altered resistance to infection. Am J Clin Nutr 1998;68(suppl):447S-63S

11 Fenwick PK, Agget PJ, McDonald D, et al. Zinc deficiency and zinc repletion: effect on the response of rats to infection with Strongyloids ratti. Am J Clin Nutr 1990;52:166-72.
12 Sazawal S, Black RE, Bhan MK, et al. Zinc supplementation in young children with acute diarrhea in India. N Engl J Med 1995;333:839-44.

13 Baqui AH, Black RE, El Arifeen S, et al. Effect of zinc supplementation started during diarrhea on morbidity and mortality in Bangladeshi children: community randomized trial. BMJ 2002;325(9):1059.

14 Sazawal S, Black RE, Bhan MK, et al. Efficacy of zinc supplementation in reducing the incidence and prevalence of acute diarrhea - a communitybased, double-blind, controlled trial. Am J Clin Nutr 1997:66(2):413-18.

15 Baqui AH, Zaman K, Persson LA, et al. Simultaneous weekly supplementation of iron and zinc is associated with lower morbidity due to diarrhea and acute lower respiratory infection in Bangladeshi children. $J$ Nutr 2003:133(12):4150-7.

16 Zinc Investigators' Collaborative Group. Therapeutic effects of oral zinc in acute and persistent diarrhea in children in developing countries: pooled analysis of randomized controlled trials. Am J Clin Nutr 2000;72:1516-22.

17 Zinc Investigators' Collaborative Group. Prevention of diarrhea and pneumonia by zinc supplementation in children in developing countries:
pooled analysis of randomized controlled trials. J Pediatr 1999;135:689-97.

18 Black RE. Zinc deficiency, infectious disease and mortality in the developing world. J Nutr 2003;133(suppl):1485S-9S.

19 World Health Organization. The treatment of diarrhea: a manual for physicians and other senior health workers. Geneva, Switzerland: WHO, 1995.

20 Subcommittee on the Tenth Edition of the RDAs of the Food and Nutrition Board. Recommended dietary allowances. Washington, DC: National Academy Press, 1989.

21 Butrimovitz GP, Purdy WC. The determination of zinc in blood plasma by atomic absorption spectrometry. Anal Chim Acta 1977;94:63-73.

22 Penny ME, Peerson JM, Marin RM, et al. Randomized, community-based trial of the effect of zinc supplementation, with and without other micronutrients, on the duration of persistent childhood diarrhea in Lima, Peru. J Pediatr 1999; 135:208-17.

23 Ruel MT, Rivera JA, Santizo M-C, et al. Impact of zinc supplementation on morbidity from diarrhea and respiratory infections among rural Guatemalan children. Pediatrics 1997;99:808-13.

24 Roy SK, Tomkins AM, Mahalanabis D, et al. Impact of zinc supplementation on persistent diarrhea in malnourished Bangladeshi children. Acta Paediatr 1998;87:1235-9.

25 Wetherilt $\mathbf{H}$, Ackurt $F$, Brubacker $G$, et al. Blood vitamin and mineral levels in 7-17 years old Turkish children. Int J Vitam Nutr Res 1992;62:21-9.

26 Kilic I, Ozalp I, Coskun T, et al. The effect of zinc-supplemented bread consumption on school children with asymptomatic zinc deficiency. J Pediatr Gastroenterol Nutr 1998;26(2):167-71.

27 Cetin N, Ozer E, Bakiler AR, et al. Akut Ishalli Sut Cocuklarinda Serum Cinko Duzeyi. Inonu U Tip F Dergisi 2003;10(2):55-7.

28 Polat TB, Uysalol M, Cetinkaya F. Efficacy of zinc supplementation on the severity and duration of diarrhea in malnourished Turkish children. Pediatr Int 2003;45(5):555-9.

29 Solomons NW, Pineda O, Viteri F, et al. Studies on the bioavailability of zinc in humans: mechanisms on the intestinal interaction of non-heme iron and zinc. J Nutr 1983;1 13:337-49.

30 Schlesinger L, Arevalo M, Arredondo S, et al. Zinc supplementation impairs monocyte function. Acta Paediatr 1993;82:734-8

31 Hamadani JD, Fuchs GJ, Osendarp SJ, et al. Randomized controlled trial of the effect of zinc supplementation on the mental development of Bangladeshi infants. Am Clin Nutr 2001;74:381-6.

32 Hamadani JD, Fuchs GJ, Osendarp SJ, et al. Zinc supplementation during pregnancy and effects on mental development and behaviour of infants: a follow-up study. Lancet 2002;360:290-4. 